\title{
Entre acordadas y gendarmes. La organización de la policía rural en Jalisco durante el siglo XIX*
}

\section{Between Acordadas and Gendarmes. The Organization of the Rural Police Force in Jalisco in the 19th Century}

\author{
Miguel Ángel Isais Contreras ** \\ (D) https://orcid.org/0000-0002-3408-3743 \\ Centro Universitario de Tonalá-Universidad de Guadalajara, México \\ migueliscon@hotmail.com
}

Resumen: El artículo detalla algunas de las experiencias que el gobierno del estado de Jalisco tuvo que ensayar en materia de seguridad pública durante el siglo xIx. La inestabilidad política y económica dentro del territorio y del

* El presente estudio se desprende del proyecto académico "Formación del Estado, justicia y administración política en Jalisco. El ejercicio del poder a nivel local durante el gobierno de Ignacio L. Vallarta (1871-1875)", que realicé en el periodo 2019-2020 en calidad de estancia posdoctoral del CONACYT, en el doctorado en Ciencias Sociales del Centro de Investigaciones y Estudios Superiores en Antropología Social, sede Occidente.

** Doctor en Ciencias Sociales por el Colegio de Michoacán, México. Posdoctorando en el doctorado en Ciencias Sociales del Centro de Investigaciones y Estudios Superiores en Antropología Social-Occidente. Líneas de investigación: historia social y cultural de México y Jalisco durante los siglos XIX y xx, abarcando temas como la criminalidad, la justicia y las representaciones culturales de los sectores populares, de las mujeres y grupos étnicos a través de prensa, literatura, fotografía, iconografía y la opinión pública.

cómo citAR: Isais Contreras, M. Á. (2021). Entre acordadas y gendarmes. La organización de la policía rural en Jalisco durante el siglo xIx. Secuencia (111), e1814. Dor: https://doi.org/10.18234/secuencia. v0i111.1814

\section{c) 98}

Esta obra está protegida bajo una Licencia Creative Commons Atribución-NoComercial 4.0 Internacional. 
país, como indicios de una fragilidad del Estado, dieron origen a la organización de fuerzas civiles de seguridad comúnmente denominadas acordadas, en alusión al extinto tribunal colonial que operó como policía rural. No fue sino hasta la segunda mitad del siglo XIX cuando el gobierno jalisciense comenzó a diseñar una policía estatal, ya no al mando de particulares sino del propio gobierno: la gendarmería del estado.

Palabras clave: policía rural; acordadas; gendarmería; Jalisco; siglo xIX.

Abstract: The article details some of the experiences the government of the state of Jalisco was forced to try out in terms of public security during the 19th century. The political and economic instability within the state and the country, reflecting the fragility of the state, led to the organization of civil security forces commonly known as acordadas, a reference to the defunct colonial court that operated as a rural police force. It was not until the second half of the 19th century that the Jalisco government began to design a state police force, no longer under the command of individuals but of the government itself: the State gendarmerie.

Keywords: rural police; acordadas; gendarmerie; Jalisco; 19th century.

Recibido: 29 de enero de 2020 Aceptado: 18 de agosto de 2020

Publicado: 6 de agosto de 2021

$E^{1}$ presente artículo es un esfuerzo por reconocer y analizar un tema que recurrentemente estuvo, y lo sigue estando, tanto en la vida pública y parlamentaria actual como en el centro de las discusiones de la historiografía política y social mexicana dedicada a la seguridad pública. Sin embargo, aunque esta cadena de estudios se extiende más detalladamente sobre la ciudad de México y el territorio federal, no alcanzan a mirar lo que sucedía en varios extremos del país. ${ }^{1}$

${ }^{1}$ Afortunadamente se cuenta con estudios, algunos ya clásicos, sobre la organización de las fuerzas militares y de seguridad pública para el largo periodo decimonónico, siendo los de Paul Vanderwood $(1982,1986)$ los que pusieron atención en el tema y a los que hoy haría 
En los últimos años desde América Latina se ha incrementado el interés por la historia del derecho desde una perspectiva menos doctrinaria, ${ }^{2}$ a través de estudios sobre los aparatos de justicia local tanto del antiguo régimen como de la fase poscolonial, ya sea para conocer la formación de esos pequeños espacios políticos y administrativos, o bien, para conocer las relaciones sociales que giraron alrededor de ellos. Bajo esta nueva perspectiva, se intenta cuestionar la operación casi ininterrumpida de los marcos institucionales de los proyectos nacionales, cuya aplicación difícilmente se ejerció sobre el campo, espacio donde la norma del legislador no llegaba con la misma frecuencia. Estas condiciones distanciaron aún más el diálogo entre las justicias del centro y las provincias al presentarse la transición de las independencias, momento en que los ayuntamientos daban cuenta de su autonomía y de su peculiar forma de administrar justicia, organizar elecciones y recaudar impuestos. Observar desde la frontera tal vez pudiera considerarse como la mejor manera de evaluar los alcances y la efectividad del Estado y de los diversos derechos que seguían en pie al margen de un Estado todavía sin forma, inoperante.

Para comprender el funcionamiento de las justicias rurales en Jalisco durante el siglo XIX es preciso conocer algunos de sus antecedentes. Desde mediados del siglo xvi el virrey Luis de Velasco autorizó la organización en Nueva España de las justicias rurales denominadas alcaldías provinciales de Santa Hermandad, ante el reclamo constante de propietarios y particulares que cotidianamente se veían afectados en sus bienes y seguridad por la acción de bandoleros, asesinos y ladrones. La Santa Hermandad ya era un modelo de seguridad rural que se venía aplicando desde la Metrópoli; y en cierta manera efectivo, pues a pesar de ser guardias de seguridad organizadas y financiadas por los particulares de cada localidad, se sujetaban a la corona. Realmente se

\footnotetext{
falta confrontar y profundizar en perspectiva regional. En torno a la organización de policías y seguridad pública, se destaca el caso de la ciudad de México, bajo los estudios de José A. Yáñez Romero (1999), Jorge Nacif Mina (1986); y más recientemente los trabajos de Diego Pulido Esteva (2017) quien, en últimas fechas, junto a otros investigadores, ha detallado aspectos de la creación y organización de la policía principalmente en las ciudades. Véase, por ejemplo, Dávalos, Hernández y Pulido (2017).

${ }^{2}$ En el giro metodológico propuesto por la "historia crítica del derecho", las leyes y el "Estado" son vistos desde una perspectiva cultural y bajo una mirada más antropológica en busca de los discursos, actores y concepciones que les dieron origen. Esta corriente ha permitido conocer otras formas de justicia y releer los aparatos de control social. Véase, por ejemplo: Agüero (2018); Barriera (2010); Rojas Gómez (2008); Fradkin (2008).
} 
sabe poco sobre la operación de la Santa Hermandad para el caso de Nueva España, y todavía menos para la Nueva Galicia; ${ }^{3}$ a lo más, es que estas alcaldías fueron organizadas por algunos ganaderos y hacendados, quienes hicieron de tal oficio un instrumento para proteger sus propios intereses (Becerra Jiménez, 2008).

Una de las funciones básicas de los alcaldes de hermandad era precisamente conocer sobre "robos, hurtos y fuerzas de bienes muebles y semovientes". ${ }^{4}$ Con estas facultades, por ejemplo, era grande la necesidad que tuvieron algunos ganaderos para que estas acciones se persiguieran de manera contundente y verificarlo personalmente. Por ejemplo, Miguel del Portillo, poseedor de fincas ganaderas tanto en Toluquilla como en Tlajomulco, solicitó ante la Audiencia de Guadalajara ser alcalde de hermandad del distrito correspondiente a sus haciendas, incluidas dos leguas a la redonda, debido a la "frecuencia de latrocinios y salteos en despoblados y caminos". En 1794 la Audiencia le autorizó fungir como alcalde de hermandad por "todo el valle de Toluquilla, [y] haciendas propias", así como cuatro leguas más a la redonda de cada una de sus haciendas. ${ }^{5}$

No fue sino hasta el siglo xviII, al ponerse en marcha las reformas borbónicas, cuando se instaló en Nueva España una institución diferente: el Tribunal de la Acordada, creado nuevamente por las presiones de los propietarios que buscaban la defensa de sus bienes. Fue una institución judicial encargada de vigilar y castigar los robos y el bandidaje que amenazaban las propiedades y la seguridad en el campo y en los caminos, y operó coordinada con la Real Sala del Crimen de la Audiencia de México. ${ }^{6}$

${ }^{3}$ Se comparte y promueve la idea de que los archivos de la justicia criminal de las distintas provincias novohispanas no están suficientemente estudiados, quizá sea por el mismo interés que ha tenido la ciudad de México sobre el resto del territorio. Así, será necesario hacer mayor investigación tanto en el Archivo General de Indias como en el Archivo General de la Nación; al igual que en los archivos provinciales y de alcaldías mayores que comprendieron, al menos y para el interés de este estudio, la Nueva Galicia.

${ }^{4}$ Ley I, tit. xxxv, libro xII. Novísima recopilación de las leyes de España (1829).

${ }_{5}^{5}$ Manuscrito 315, Papeles de Derecho, vol. I, 1800, f. 290v. Biblioteca Pública del Estado de Jalisco "Juan José Arreola" (en adelante APEJ), Zapopan, Jalisco, México.

${ }^{6}$ Los estudios sobre el Tribunal de la Acordada se han presentado de manera aislada a través de los últimos 50 años. El primer trabajo es la tesis de Alicia Bazán Alarcón (1964), seguida por las de Barbara G. Montgomery (1973) y Colin MacLachlan (1976) que, al igual que Bazán, construyen su investigación con fuentes provenientes del Archivo General de la Nación. Más recientemente, Odette Rojas (2012) retoma el conflicto que se desató entre la Real Sala del Crimen y el Tribunal de la Acordada debido a las muchas atribuciones que adquirió este 
La creación de la Acordada en Nueva Galicia tuvo un origen semejante, pues la persona más interesada en instalar un tribunal de tales características fue un acaudalado propietario de Ahualulco: Manuel del Río, quien como militar y subdelegado creyó estar en la mejor posición para ver por el bienestar de sus cosas bajo una propuesta que pudieron haber apoyado más propietarios como él. Aunque poco se sabe sobre las operaciones de la Acordada en Nueva Galicia, ${ }^{7}$ las acciones de Manuel del Río son un excelente eslabón para conocer los últimos años de ese tribunal. Esto pese a los estudios de MacLachlan (1976) o Bazán Alarcón (1964), entre otros, quienes han confirmado que la Acordada fue desarticulada por las Cortes de Cádiz en 1812, y se sobreentiende, que esto debió aplicarse inmediatamente en el centro de Nueva España, no así en los reinos más separados de este.

\section{GUADALAJARA Y SUS JUSTICIAS RURALES}

Cabe mencionar que el Tribunal de la Acordada se extendió formalmente, por orden del virrey Bucareli, hasta Nueva Galicia en 1776 a través de sus tenientes o agentes locales. ${ }^{8}$ Hipólito Villarroel (1994, pp. 121-122), quien además fue asesor de la Acordada, confiaba en su utilidad para la seguridad del virreinato, y por tanto creyó pertinente instalar un tribunal en la capital de Nueva Galicia. El tribunal contaría con las mismas "facultades y prerrogativas" que el de la ciudad de México, con el que mantendría comunicación y auxilio.

Aunque el sistema de intendencias debilitó el poder de la Acordada, a nivel local las elites se hicieron de esa nueva estructura política para formar guardias de seguridad que incluso fueran reconocidas por la corona (Gutiérrez, 1991, p. 356). Ese fue el caso de Manuel del Río, quien como subdele-

al aplicar justicia sin el procedimiento debido. Y, finalmente, está la investigación de Patricio Hidalgo (2013), quien a diferencia de sus antecesores estudió la criminalidad rural en la Nueva España con fuentes especialmente obtenidas del Archivo General de Indias.

7 María Ángeles Gálvez Ruiz (1996), con base en documentos del Archivo General de Indias, ofrece valiosa información sobre la Acordada en Nueva Galicia, pues no sólo habla de una institución que buscó extender su control sobre los caminos y despoblados más remotos del centro del virreinato, sino que además generó una resistencia entre las autoridades novogalaicas que buscaron instalar instituciones propias.

${ }_{8}$ Ramo Civil. Caja 446, exp. 10, prog. 7358, fs. 120f-120v. Biblioteca Pública del Estado de Jalisco "Juan José Arreola", Archivo Histórico de la Real Audiencia de Guadalajara (en adelante APEJ, AHRAG), Zapopan, Jalisco, México. 
gado en Ahualulco intentó ejercer también como juez de Acordada para el territorio de Nueva Galicia. Aunque se tenía conocimiento de las previas solicitudes que hizo Manuel de Río para fungir como "Comandante en Jefe de la Acordada en la Nueva Galicia”, los fiscales de la Audiencia insistieron en que el tribunal de Guadalajara debía quedar sujeto a la Audiencia de Nueva Galicia (Bazán Alarcón, 1964, pp. 205-206). De hecho, sus pretensiones iban todavía más lejos, pues había propuesto al virrey Branciforte la construcción de un juzgado, una cárcel y la manutención de sus reos a través del incremento en algunos peajes, de los excedentes de repartimientos, de los decomisos de bebidas prohibidas y de otras contribuciones que recibiera la ciudad de Guadalajara, misma que sería sede del nuevo tribunal (Gálvez Ruiz, 1996, pp. 289-290). Sin embargo, Branciforte sólo lo distinguió como teniente y representante de la Acordada. ${ }^{9}$

No obstante, hubo al parecer más razones para desestimar la instalación de un tribunal de la Acordada que fue más a iniciativa de particulares que de la Audiencia de Guadalajara, pues desde el siglo xvirI la incursión de los tenientes de Acordada en territorio novogalaico trastocó la administración de justicia dentro de los pueblos al toparse con la jurisdicción de los alcaldes de hermandad: autoridades judiciales que a nivel estrictamente local perseguían a los infractores que ahora pretendía concentrar la Acordada. Ante la introducción de los tenientes de Acordada, estos quedaron por encima de los alcaldes de hermandad, y en adelante debieron actuar bajo las órdenes del Real Tribunal y con independencia de la sala del crimen de la Audiencia (MacLachlan, 1976, pp. 114-115).

Posiblemente las quejas de la Audiencia de Guadalajara no cesaron frente a las acciones de los tenientes provinciales, quienes debían presentar su pase de título como comisarios de Acordada. Pero algunos no respetaban tales disposiciones, al grado de que en 1799 se le informó al juez mayor de Acordada sobre la corrección que se hizo al teniente provincial Nicolás Garavito, quien parecía actuaba con poca consideración de los ministros y alcaldes ordinarios, sin dar cuenta a su jurisdicción y sin siquiera conducirse "por oficio o de palabra”. Tal parece que el teniente Garavito además perseguía

${ }^{9}$ Eric Van Young (1989, p. 304) encontró y calificó a este singular personaje como un terrateniente "descarado", "agresivo y falto de principios" que en colusión con el alcalde y el párroco de Ahualulco, se apropió cada vez de las tierras adyacentes a su hacienda, al grado incluso de apoderarse de casas y huertos, así como de construir caminos que conectaran sus propiedades con el pueblo. 
arbitrariamente cualquier delito, sin respetar aquellos que eran materia de los alcaldes ordinarios. ${ }^{10}$

A principios del siglo xIx la falta de coordinación entre la Acordada y las justicias locales novogalaicas llegaron a tal punto que los reos eran quienes llevaban la peor parte, pues al mantenerse varias comunicaciones entre el juez del Real Tribunal y los alcaldes ordinarios (algo que incluso se prolongaba por meses), los reos quedaban en la cárcel real de la Audiencia hasta recibir su sentencia. Los tenientes de Acordada se encargaban precisamente de la aprehensión de todo sospechoso de robo, mientras que las justicias ordinarias locales preparaban los sumarios para que así, y a la distancia, el juez del Real Tribunal emitiera su sentencia, o bien, aconsejara a los jueces ordinarios sobre qué proceso debía continuar la causa.

Tras la muerte de Antonio Columna en 1812 se nombró como juez de la Acordada a quien entonces fuera capitán del regimiento de dragones de Nueva Galicia, Luis Quintanar, cargo que finalmente no llegó a tomar debido a las rebeliones insurgentes. De cualquier manera, el tribunal fue disuelto con el surgimiento de la Constitución de Cádiz. Pero, ¿realmente se tuvo conocimiento de ello en los juzgados locales? El caso de Manuel del Río nos lleva a plantear esta pregunta, pues en la Intendencia de Guadalajara la justicia rural mantuvo en funcionamiento la Acordada aún después de 1814, aunque más por desconocimiento que por el interés de mantener las atribuciones de quienes representaban aquel tribunal.

Así, a inicios de 1815 Manuel del Río continuaba actuando como juez de Acordada por varias subdelegaciones aun cuando este tribunal ya estaba aparentemente extinto. Ante las autoridades locales, del Río es referido como el juez, jefe principal o "comandante en jefe" del real tribunal de la Acordada. En tal condición, persiguió y hasta juzgó a ladrones y abigeos que particularmente afectaban sus propiedades y las de sus vecinos, valiéndose de sus opiniones y de la "pública voz y fama" de varios detenidos. ${ }^{11}$ México.

${ }^{10}$ Manuscrito 315, Papeles de Derecho, vol. II, 1800, f. 329v. BPEJ, Zapopan, Jalisco,

${ }^{11}$ Causa criminal contra Onofre Andrade, alias Marañas, por hurtos de bueyes, 1815, caja 65, prog. 2579, f. 18, BPEJ, AHRAG, Zapopan, Jalisco, México; Isais (2017). 


\section{NUEVAS JUSTICIAS RURALES: GUARDIAS Y ACORDADAS}

Los primeros gobiernos de Jalisco no sólo se preguntaron por cuál legislación aplicar al momento de organizar una nueva administración de justicia, sino además qué clase de autoridades había que instalar en todo el territorio del estado. Al presentar su primer informe de gobierno en 1826, Prisciliano Sánchez dio cuenta de la difícil tarea que representaba transformar tanto las justicias como los gobiernos políticos en el interior del estado, y por más que se reglamentara su creación como lo dictaba la constitución recién adoptada, en muchos municipios continuó el "triste abatimiento e ignorancia en que se mantuvo a los americanos por tantos años". A diferencia del ímpetu mostrado cuando fue legislador, reconoció que la implementación del sistema republicano sería lenta, y sin la ayuda de instrucciones sencillas y "acomodadas a su alcance" (como manuales y cartillas para formar padrones y elecciones, recaudar fondos y administrar justicia) sería igualmente imposible inculcarles el amor patrio.

Las justicias rurales de comienzos del siglo xIX operaban comúnmente por influjo de la costumbre y el sentido común propio de cada localidad. Se trataba de distintos niveles de justicia que no sólo impartían las autoridades reconocidas por la corona o el Estado, sino además de ciertos grupos de poder que incluso fueron forzados a aplicarla. Ya fueran los borbones o los sucesivos gobiernos liberales, ambos encontraron en el prestigio e influencia de hacendados y propietarios locales la ruta para poder instalar cierto orden y seguridad adonde las autoridades del centro no alcanzaban siquiera a observar.

Durante los primeros años del periodo independiente, resulta impensable la justicia rural sin la existencia de las milicias cívicas, y posteriormente de las denominadas "guardias nacionales". Sobre sus operaciones realmente se sabe poco para el caso de Jalisco, y una noticia interesante se puede obtener de las memorias del viaje que hizo en 1850 a su paso por los Altos de Jalisco la soprano inglesa Anna Bishop (1852). En su trayecto encontró patrullas compuestas por agricultores y residentes de los pueblos que protegían los montes y los caminos de los ladrones, aunque posiblemente estas fuerzas fueron más visibles debido a su visita. Una impresión semejante se llevó el británico Alexander Clark Forbes (1851, pp. 156-169), quien además de haber quedado maravillado por los paisajes que encontró a lo largo del río Santiago a su paso por Tepic, también llamó su atención la manera en que aplicaban 
justicia las guardias nacionales tras ver cómo ejecutaron a un hombre que había asesinado a media docena de personas. Sin embargo, consideró que si aquel fue ejecutado fue más por no haber tenido el capital para evitarlo, pues si se tenía el suficiente dinero para pagar a un juez, era muy posible obtener la libertad. Finalmente quedó convencido que, ante una falta en casi todo el país de jueces letrados, la administración de justicia se mantendría inoperante. No obstante, esta poca efectividad o desconfianza que se tenía de las guardias nacionales y las milicias cívicas se debió a que los gobiernos locales y los estatales, al tratar de organizar sus propias fuerzas de seguridad, tuvieron que coordinarlas con las del gobierno federal (en buena medida ausentes e intermitentes), pero también a su incapacidad de mantenerlas organizadas entre una administración y otra.

Terminar con el bandolerismo y los asaltos en los caminos fue preocupación casi de todas las entidades del país durante el siglo xIX, y la falta de coordinación entre las altas autoridades fue la constante. Por ejemplo, en 1848 el Supremo Tribunal de Justicia de Jalisco denunció al ejecutivo local que las sucesivas revoluciones generadas por los vertiginosos cambios políticos no dejaron sino desorden social a su paso. Declaraba que se vivían tiempos en donde aquellos que habían formado parte de las milicias en defensa de un régimen, ahora integraban bandas criminales, debido especialmente a la inadecuada implementación de las guardias nacionales. Si ese ambiente de inseguridad se mantenía en la mayor parte del territorio, no era porque la ley no se aplicara; es decir, no era responsabilidad del sistema judicial, sino que se debía a la inobservancia de las leyes y la ineficacia de las policías para prevenir los delitos. La alusión iba directamente contra los representantes del poder ejecutivo y legislativo: los comisarios y los legisladores, respectivamente (Manifestación, 1848). El gobernador José Guadalupe Montenegro exigió al Tribunal y su presidente poner remedio a ese ambiente de inseguridad, motivo por el cual y a regañadientes debieron presentar casi de manera inmediata un proyecto de ley para perseguir a ladrones y asesinos.

El nuevo proyecto distó de ser original al menos en su definición, no así en la manera de medir el tipo de condenas, pues mientras que el robo violento se castigaba según el decreto de 1826 hasta con ocho años de prisión; en el de 1848, aprobado en 1851, el mismo delito se castigaría con la pena de muerte. Si el gobierno quería que el Tribunal aportara una iniciativa para prevenir esos delitos, la respuesta de este no pudo ser otra a sabiendas de la poca consideración que tuvieron con las garantías de los agresores. Así lo demostró 
el artículo $8^{\circ}$ del proyecto al proponer "la pena de muerte lenta", que consistía en colgar del cuello a los delincuentes hasta morir. Pero si tal medida era repugnante entre los jaliscienses, otra opción que encontraron viable fue la del garrote o mascada, pena que al final se incluyó en la ley. La comisión del Tribunal tal vez pudo haberse sentido decepcionada, pues creyó necesario imprimir "cierto aparato de horror" a esta clase de ejecuciones, como hubiera sido: "vestir al ajusticiado con un saco, en que por el pecho y la espalda hubiese un tigre pintado, signo de la ferocidad; es preciso convencerse de que estas apariencias obran maravillosamente en el pueblo, que no es filósofo en ninguna parte, ni vive de abstracciones" (Proyecto de ley, 1848, p. 18). ${ }^{12}$

Efectivamente, el aparato legal y judicial fijó mayor rigor a las sanciones contra ladrones y asesinos, pero todavía no se pensaba a mediados de ese siglo en una policía mejor estructurada. En aquel tiempo, se confiaba en el funcionamiento de las acordadas, en buena medida porque no le generaba un egreso al gobierno, sino a los particulares más interesados. Desde 1857 se formaron en Jalisco las denominadas "acordadas", que mantuvieron una estructura similar a la que encabezaron los alcaldes de hermandad y en evidente alusión al anterior tribunal colonial. Las acordadas jaliscienses fueron uno de los instrumentos con que contó el gobierno del estado para contener, en momentos de supuesta emergencia, la criminalidad rural y, a su vez, para involucrar a la sociedad, en especial a sus elites locales, con la seguridad pública. Estos últimos tenían la obligación de perseguir y de vigilar que en las haciendas y ranchos no se emplearan sospechosos. Tanto los integrantes de las acordadas como sus jefes eran acreedores de ciertas garantías pues, así como a los primeros se les exceptuaba de toda carga concejil durante ese ejercicio, los jefes podían exigir gratificaciones. En cierta manera no existió en la letra ninguna restricción aparente para la designación de los jueces de acordada, quienes sólo debían ser propuestos a los jefes políticos por medio de las autoridades locales. Una decisión que al final supuestamente tendría el gobernador. ${ }^{13}$

De tal manera, es imposible comprender el funcionamiento de las acordadas sin la autoridad del jefe político quien, como fiel representante e intermediario del gobernador, así como organizaba las acordadas bajo "las

${ }^{12}$ El artículo aprobado tampoco fue en sentido alguno menos atemorizante, ya que, si el propósito era ejemplificar el castigo entre la población, al final se resolvió que el cadáver de cada uno de los condenados sería colocado donde hubiera cometido su delito. Colección de los decretos (1823-1913, t. XII, $1^{\text {a }}$ serie, p. 467).

${ }^{13}$ Colección de los decretos (1823-1913, t. xIv, $1^{\text {a }}$. serie, pp. 240, 250). 
exigencias de cada localidad", ${ }^{14}$ garantizaba que los intereses de algunos particulares no rebasaran derechos y atribuciones que estuvieran por encima de las que reconocía el ejecutivo. Se trataba entonces de una negociación entre el gobierno y los particulares, a quienes se permitió seguir ejerciendo el control y la seguridad de sus localidades bajo plena supervisión del gobierno. Uno de los gobernadores que buscó estar al tanto de la operación de las acordadas en el interior del estado fue precisamente Ignacio L. Vallarta, quien a través de los jefes y directores políticos fue informado no sólo de cómo funcionaban, sino además quiénes las operaban y sobre los posibles abusos que cometían. Sin embargo, lo que más le interesaba era que realmente estuvieran dedicadas a la persecución de los bandidos y gavillas.

Por ejemplo, en 1874 fue notificado por el director político de San Gabriel de las operaciones de la gavilla de Ángel Rodríguez y que el pueblo de Apulco tenía la intención de liquidarlo. Para prevenir tal acto, le dijo que contaba con los servicios de la acordada local, expresando así al gobernador la buena disposición que tenía al frente de ella. ${ }^{15}$ De la misma manera lo hizo el director político de Zapopan, quien le informó sobre las acordadas formadas en la "hacienda de Santa Lucia" para perseguir a la gavilla del Chino Cardona. ${ }^{16} \mathrm{O}$ de la acordada del rancho de Cuchillas (del departamento de Zapotlanejo), cuyo propietario, Gil Murguía, había reunido para perseguir a la gavilla de los hermanos Lomelí y puesto a las órdenes del director político. ${ }^{17}$ Zapotlanejo era un punto por demás importante para el comercio y la economía de Guadalajara, pues por ahí entraban y salían las mercancías, correspondencia y viandantes que se conectaban con el Bajío y el centro del país. Cuando fue creada la gendarmería en 1868, el gobierno apuró en destinar fuerzas hacia aquel paso, ${ }^{18}$ pero durante la administración de Vallarta, el punto continuaba asediado por múltiples gavillas, al grado de que fueron redobladas las acordadas. ${ }^{19}$

${ }^{14}$ Colección de los decretos (1823-1913, t. IV, 2 $2^{\mathrm{a}}$. serie, p. 584).

${ }^{15}$ Ignacio Vallarta Papers, carp. 21 (Correspondencia con Teófilo Guadarrama). Biblioteca Nettie Lee Benson (en adelante BNLB), Universidad de Texas, Austin, Texas, Estados Unidos.

${ }^{16}$ Ignacio Vallarta Papers, carp. 19 (Correspondencia con José María Meza). BNLB, Universidad de Texas, Austin, Texas, Estados Unidos.

${ }_{17}$ Ignacio Vallarta Papers, carp. 4 (Correspondencia con Ramón Ortiz). BNLB, Universidad de Texas, Austin, Texas, Estados Unidos.

${ }_{18}$ Colección de los decretos (1823-1913, t. III, $2^{\mathrm{a}}$. serie, p. 473).

${ }^{19}$ Ignacio Vallarta Papers, carp. 4 (Correspondencia con Ignacio de la Torre). BNLB, Universidad de Texas, Austin, Texas, Estados Unidos. 


\section{LA GENDARMERÍA DE JALISCO}

A partir de 1876 el gobierno del estado intentó nuevamente poner control a las acordadas, en tanto que no eran fuerzas realmente adiestradas en el uso de las armas, o bien, porque solamente acudían al auxilio e intereses de algunos particulares. De tal manera se intentó nuevamente, mediante el remplazo, concretar un proyecto de guardia nacional, pero bajo el completo control del gobierno del estado de Jalisco, a través de la Gendarmería del Estado. Se esperaba tuviera éxito y se pedía a los ayuntamientos colaborar en su formación, pero no fue sino hasta 1882 cuando se reestructuró bajo un nuevo reglamento (cuatro escuadrones de caballería con 250 soldados y una sección de infantería con 120 soldados).

No obstante, la gendarmería comenzó a funcionar y definirse como tal desde 1861, poco tiempo después de haber llegado al gobierno del estado el general Pedro Ogazón, quien entre sus distintas faenas por remediar el precario estado de la administración pública y, muy posiblemente, de limitar las labores de las acordadas y complementar las de la Guardia Nacional, comenzó por instalar una caballería de gendarmes (Trujillo Bretón, 2010). Tales fuerzas quedarían organizadas y estructuradas desde los cantones hasta los municipios, bajo la misma lógica en que estaba dividida la administración política. Así, en las cabeceras de cantón, la gendarmería quedaba bajo las órdenes de los jefes políticos; en los departamentos, por los subinspectores; $y$ en los municipios, por los comisarios de policía, mismos que simultáneamente supervisaban las acciones de las acordadas. En las haciendas también se instalaría una mínima fuerza compuesta a lo más por diez gendarmes, pero un cambio que se logra distinguir en ese momento, al menos en la letra, es que su sostenimiento correría por cuenta de las autoridades políticas locales. Esto daba a entender que el gobierno deseaba monopolizar la política de seguridad y hacerse presente a través de un contingente que a la vista cualquiera pudiera reconocer, pues además de estar montadas con "buenos caballos" y con "sillas del país", su indumentaria quedaría compuesta de pantalón, chaqueta de cuero, y un sombrero que visiblemente mostrara la leyenda: "Seguridad pública". ${ }^{20}$

Sin embargo, no sería sino hasta 1868 cuando el gobierno, entonces encabezado por Emeterio Robles Gil, nuevamente intentó formalizar la gendarmería ya no sólo a través de una caballería, sino además de un amplio

${ }^{20}$ Colección de los decretos (1823-1913, t. I, $2^{\mathrm{a}}$. serie, pp. 444-448). 
contingente de infantería, para lo cual emitió un decreto para el reclutamiento voluntario de elementos. Se refrendó que actuaría conforme a la jerarquía político-administrativa del estado. De tal manera, este incipiente reglamento distribuyó las fuerzas desde el centro (el territorio de la capital) hacia las periferias: las cabeceras de cantón y departamentos que los constituían. Así, a Guadalajara la dotaba de 160 gendarmes de a caballo y 40 infantes; a los cantones, 25 gendarmes montados; y a los departamentos, sólo diez. Un cambio sensible en ese momento era la aparente desprotección en la que quedaron los ayuntamientos, los cuales ahora debían solicitar su ración de seguridad bajo justificadas razones. Situación que ponía en evidencia la poca coordinación, y hasta desconfianza, que se daba entre los alcaldes y los representantes directos del gobierno del estado: jefes y directores políticos. ${ }^{21}$

La mala organización de la gendarmería se hizo cada vez presente al no contar con una reglamentación completa y clara. Lamentablemente, sus operaciones no eran posibles sin un financiamiento estable, pues al poco tiempo varios ayuntamientos declararon no contar con los fondos para mantener sus propias guardias. Así, parecía que el 1\% de los ingresos del estado que se había establecido para el mantenimiento de la gendarmería no sería capaz de estructurarla. Sucesivamente se lanzaron leyes para ajustar el financiamiento y la organización de la gendarmería, hasta que el gobierno decidió en 1869 no gravar los fondos municipales y sostener completamente a las fuerzas de seguridad con el erario del Estado. ${ }^{22}$

En julio de 1869 se publicó un incipiente reglamento (el primero de varios) que impulsó el entonces gobernador, Antonio Gómez Cuervo. Desde ese momento, se estableció que la gendarmería contaría con dos escuadrones de caballería, en total, 168 gendarmes; de la misma manera tendría dos compañías de infantería, alcanzando un total de 166 elementos. Los jefes y oficiales que estarían al frente de cada fuerza serían designados por el gobierno, con la condición de demostrar honradez, aptitudes y nunca haber servido al anterior imperio.

En cuanto al contingente, su reclutamiento sería voluntario y con un tiempo de servicio de dos años. No obstante, se impusieron algunos requerimientos particularmente físicos, como contar con "robustez y aptitud", no

${ }^{21}$ Colección de los decretos (1823-1913, t. III, $2^{\text {a }}$. serie, pp. 284-289).

${ }^{22}$ Colección de los decretos (1823-1913, t. III, $2^{\text {a }}$. serie, pp. 528, 538). 
tener lesiones y una estatura por encima del metro y medio. ${ }^{23}$ Parecía haber mucha prisa por organizar la gendarmería de parte de Gómez Cuervo, pues se aproximaba la visita del secretario estadunidense William $\mathrm{H}$. Seward.

Esto guarda relación con las críticas que desde un comienzo recibió el gobierno del estado por la onerosa organización de la gendarmería. Entre uno de sus argumentos, el gobernador Jesús Leandro Camarena (1875-1879) añadió que la federación era incapaz de prodigar seguridad en los caminos de los estados; razón por la cual fue pensada y fortalecida la gendarmería. Su rechazo a las críticas de la prensa fue terminante, pues reducir a la mitad el contingente de la gendarmería era un error cuando la inseguridad en el estado estaba generalizada. Sólo si se disiparan "los nubarrones formados en el horizonte político de la República" sería posible reducir el gasto en la gendarmería; no obstante, el entonces panorama de inseguridad hacía imposible instaurar la paz pública. ${ }^{24}$ Las críticas hacia el gobierno continuaron.

Durante 1890 algún sector de la opinión pública de Guadalajara, particularmente desde los periódicos el Diario de Jalisco y la Gaceta Mercantil, aún criticaba lo costoso que era para el gobierno de Jalisco mantenerla y, sobre todo, conservar en su seno al general Sabas Lomelí, quien contaba con el respaldo de los liberales jaliscienses. En repuesta y defensa de la gendarmería, Juan Panadero descalificó a los columnistas de aquellos diarios al creerlos ignorantes de lo que se vivía realmente en el estado, pues 846 elementos (que eran los efectivos con los que contaba entonces la gendarmería) eran insuficientes para la "endemoniada comisión" de conservar la seguridad en un territorio que superaba los 70000 kilómetros cuadrados de superficie. Tras hacer un cálculo aritmético, cada gendarme era responsable de poco más de 80 kilómetros cuadrados; de tal manera que reducir el presupuesto de la gendarmería a la mitad, como sugería el Diario de Jalisco, resultaba un disparate. Pero más atrevido les parecía a los redactores de Juan Panadero ir contra la investidura y persona de Sabas Lomelí: "Este general conoce y sirve con entusiasmo y rara inteligencia la delicadísima comisión que se le confía, no solamente ahora, sino desde hace mucho tiempo, pues ejerciendo las mismas funciones durante la administración Gómez Cuervo, mereció muy grandes

23 "Reglamento a que debe sujetarse la Gendarmería del Estado", Colección de los decretos (1823-1913, t. III, $2^{\text {a }}$. serie, p. 568).

${ }^{24}$ Jesús Leandro Camarena, "Memoria que el ejecutivo del Estado Libre y Soberano de Jalisco presentó a la Legislatura” (1875-1879), en Urzúa Orozco y Hernández (1988, t. I, pp. 578-579). 
elogios de un extranjero notable, de un estadista eminente como Mr. Seward, el compañero de Lincoln."25

Efectivamente, William H. Seward fue secretario de Estado de Abraham Lincoln, y como sucesor ideológico tras la muerte de este, trató de mantener lazos con el gobierno mexicano en plena república restaurada. Durante 1869 y 1870 visitó México mediante una travesía que lo llevó a conectarse con autoridades locales y regionales a su paso desde las costas de Colima hasta la ciudad de México. No obstante, el responsable de recopilar las memorias de tal travesía fue el explorador y periodista Albert S. Evans, quien acompañó a Seward en todo momento. De acuerdo con Evans (1870), cuando decidieron partir de Colima para Guadalajara en octubre de 1869, ya los esperaba el coronel Sabas Lomelí, finamente ataviado y con 100 elementos de caballería de la gendarmería de Jalisco. Como se verá, las memorias de Evans son importantes para dar cuenta de una peculiar representación de la gendarmería con que contaba el estado de Jalisco.

En su marcha hacia Zapotlán, Evans hizo mención de los paisajes, de las costumbres y vestimenta de la gente que los veía pasar, de la comida y de lo accidentado de los caminos. Sin embargo, también llamó su atención el dispositivo de seguridad que, por órdenes de Sabas Lomelí, se extendió a lo largo de su recorrido. Así, observó que se había instalado una gran cantidad de soldados de infantería de la gendarmería, de quienes sólo prestó admiración:

Nuestra guardia de seguridad no fue objeto de menor curiosidad y admiración. Ellos pertenecían a una fuerza de 800 hombres armados, equipados e instalados en los campos por el gobierno de Jalisco para liberar los caminos de ladrones y mantener el orden público. El coronel Sabas Lomelí, su comandan-

25 "La gendarmería", en Juan Panadero, Guadalajara, 24 de abril de 1890, p. 1. Es interesante contrastar la postura que tenía el periódico Juan Panadero de la gendarmería del estado en relación con la policía municipal de Guadalajara, pues mientras que para la primera expresó su respaldo en la grande labor de garantizar la seguridad en los caminos, para la segunda no hizo sino rechazar en repetidas ocasiones el desorden y el pésimo adiestramiento de los gendarmes de la ciudad, al decir despectivamente que se componía en su mayoría de indios o de criminales, era una policía "primitiva", la cual tampoco se cansaban de comparar con la de la ciudad de México. Aquel malestar se puede comprender por el desconocimiento que tenían de las autoridades locales, en particular de los jefes políticos que se instalaron en la ciudad, a quienes sólo veían como ambiciosos e indiferentes con los problemas de la ciudad, pero sobre todo por la estima que tenían hacía el general Lomelí. Véase "La policía", Juan Panadero, 14 de octubre de 1888, núm. 1975, p. 1, Guadalajara. 
te, es un hombre de aspecto espléndido, alto, robusto, de justa complexión, con largas patillas y bigotes, a la Americano, y no sólo bien parecido, sino con el aire y la presencia de un soldado (Evans, 1870, p. 79).

Quizá por la aparente empatía que Evans sintió hacia Lomelí, entre otras cosas, por su porte americano y por garantizarle seguridad a lo largo de su trayecto, no reparó en atribuir más virtudes tanto a él como a su gendarmería, pues como "oficial valiente y consumado", en pocos meses al frente de la gendarmería aseguró prácticamente todos los caminos del estado al perseguir a ladrones y al capturar y asesinar a cerca de doscientos bandidos. Parecía que Lomelí no dejaba de querer impresionar a Evans sobre los grandes resultados que se tenían en Jalisco para establecer la seguridad pública, pues justo el último día de su visita a Guadalajara, le informó sobre la reciente captura de otro ladrón, a quien dispararon y dejaron mortalmente herido; asimismo de otros dos ladrones que ya estaban sentenciados a muerte en la prisión del estado, a quienes, le dijo, liquidarían inmediatamente. Incluso, los padres de ambos sentenciados acudieron con Seward para que intercediera por ellos en la ciudad de México, "pero estaban en sus tumbas mucho antes de que llegáramos a Guanajuato”, agregó Evans (1870, pp. 156-157).

Evans no dejó de impresionarse de la manera en que estaban organizadas las fuerzas de seguridad, particularmente la gendarmería. Así, también llamó su atención la imagen de sus capitanes, muy parecidos a los de las fuerzas estadunidenses: armados con espadas, revólveres sistema Colt y mosquetes Springfield; al igual los oficiales, quienes portaban menos armamento, pero ataviados con un uniforme brillante y pintoresco (véase imagen 1).

Evans también lanzó algunas de sus impresiones sobre los soldados de infantería, que en su mayoría eran de "sangre india". Aunque de talla pequeña, eran activos y contaban con el adiestramiento necesario para las marchas y la guerra: "Nunca había visto a hombres tan disciplinados y ordenados" (Evans, 1870, p. 81). Sin embargo, tampoco dejó de llamar su atención las limitadas raciones que recibía esta fuerza, cuya alimentación simplemente era a base de frijoles y tortillas, lo cual le parecía contrastar con la impoluta imagen de Lomelí y que quizá pudo haber inspirado las críticas de algunos diarios de Guadalajara, como se hizo mención arriba. Así, Evans no terminaría la imponente descripción de Lomelí al resaltar los accesorios que portaba: un magnífico anillo con diamante y un reloj de oro, así como una ostentosa montura ornamentada con plata sobre un fino caballo negro. 


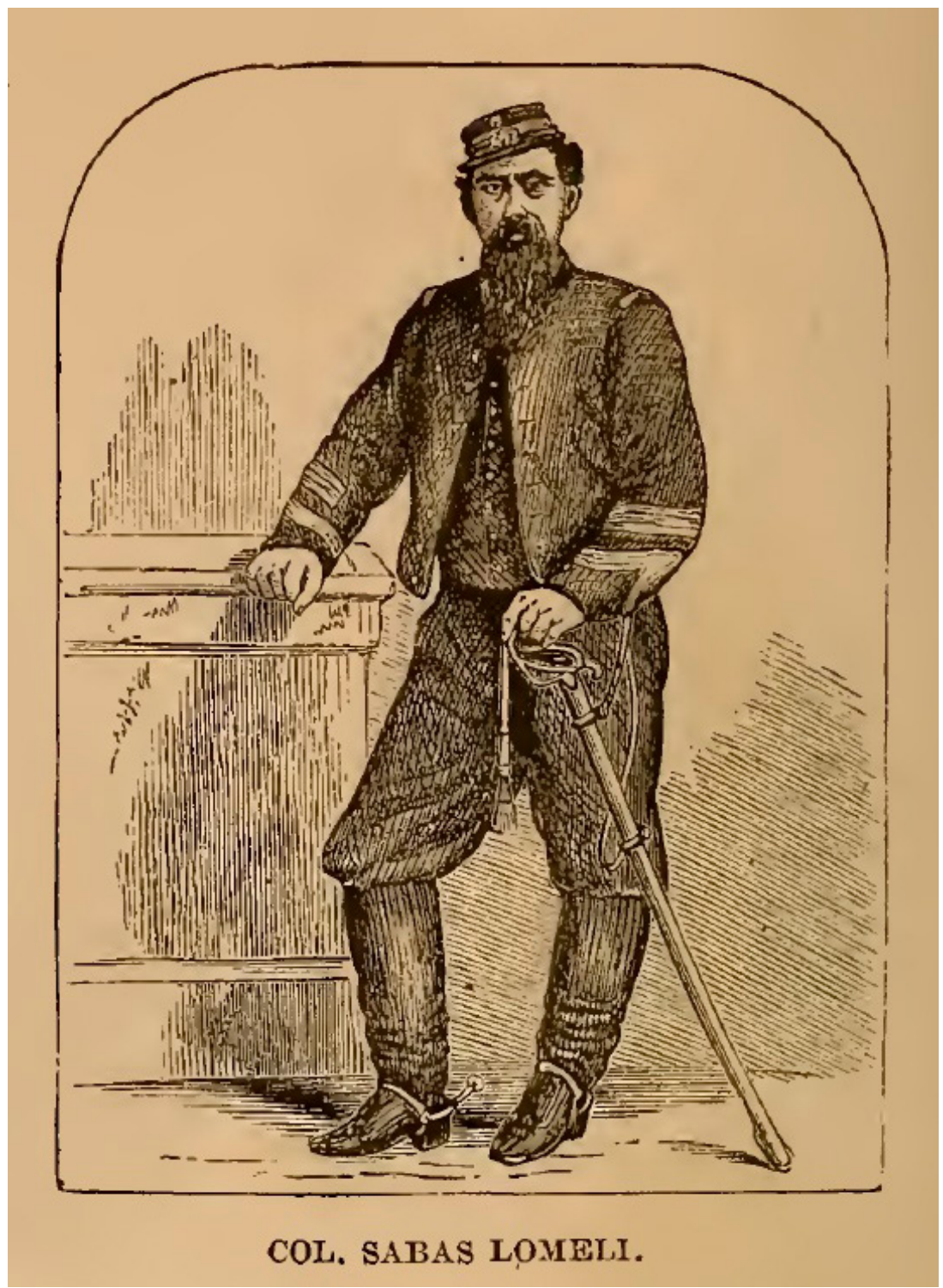

Imagen 1. Coronel Sabas Lomelí, tomada de Evans (1870, p. 80). 
Después de la visita de Seward, la gendarmería nuevamente fue objeto de reformas, dado que el gobernador Félix Barrón disolvió el reglamento un par de años después, bajo el argumento de que debería contar con una organización más civil; lo cual tampoco quería decir que la gendarmería desapareciera, sólo su mando jerárquico que se había concentrado en los jefes y capitanes de formación militar quienes serían sustituidos por inspectores y comisarios. De igual manera, la supervisión de las fuerzas de la gendarmería volvió a los jefes políticos, acción misma que garantizaba al gobierno del estado tener pleno control de las fuerzas. ${ }^{26}$ Pese a ello, Sabas Lomelí continuaría al frente de ella por varios años más, lo cual tenía mucho sentido con la modificación que hizo Ignacio L. Vallarta en 1871 de nueva cuenta a la gendarmería con la creación de un nuevo reglamento, que para entonces quedaría compuesta por cuatro secciones de caballería y una de infantería. ${ }^{27}$ En opinión de Vallarta, no era del todo atinado haberla constituido civilmente, pues en los casos de extrema agitación y revoluciones, una fuerza civil no tendría capacidad de actuar al no contar con la disciplina ni el rigor de la ley militar: "la fuerza civil no es más que una aglomeración de hombres que en peligro dispersa, que la primera dificultad pone en desorden". ${ }^{28}$ Tampoco les daba todo el respaldo a las autoridades políticas de los pueblos para dirigir las fuerzas, sólo cuando el gobierno se los dispusiera.

Conforme avanzaron los años, el proyecto concreto de una Guardia Nacional que inició desde 1868 quedó constituido a través de la gendarmería, la cual adquirió todas las funciones y reconocimiento de aquella. ${ }^{29}$ Sus elementos, pese a no tener fuero, podían ser encarcelados y procesados en los propios cuarteles y cumplir su condena en una prisión militar. Ante la incertidumbre que podía generar una fuerza de organización militar, en 1876 se indicaba que sus jefes y oficiales se conducirían "como ciudadanos que mandan a ciudadanos". No fue sino hasta 1882 cuando el nuevo reglamento de la gendarmería separó finalmente a las autoridades políticas locales de los mandos, con las cuales sólo se acudiría para una cooperación en la salvaguarda del or-

${ }^{26}$ Colección de los decretos (1823-1913, t. IV, $2^{\mathrm{a}}$. serie, p. 295; t. III, $2^{\mathrm{a}}$. serie, pp. 335-368).

27 "Reglamento a que debe sujetarse la Gendarmería del Estado", Colección de los decretos (1823-1913, t. IV, 2 $2^{\mathrm{a}}$. serie, pp. 369-382).

${ }^{28}$ Ignacio L. Vallarta, "Memoria presentada por el ejecutivo a la Legislatura del estado de Jalisco, dando cuenta del uso que hizo de las facultades extraordinarias que ejerció desde el 5 de enero hasta el 31 de octubre de 1872”. En Urzúa Orozco y Hernández (1988, t. I, pp. 540-541).

${ }^{29}$ Colección de los decretos (1823-1913, t. vi, $2^{\mathrm{a}}$. serie, p. 246). 
den público. Jefes y directores políticos ya no serían quienes organizaban las fuerzas, ni siquiera quienes podían disponer de ellas; al contrario, ahora los jefes y oficiales de la gendarmería podían exigir el auxilio de las autoridades locales para la aprehensión de gavillas y malhechores. ${ }^{30}$

De acuerdo con El Monitor Jalisciense, periódico que a pesar de autodenominarse independiente actuaba como un portavoz más del gobierno del estado al ser la principal tribuna editorial del Partido Liberal de Jalisco, en 1883 detallaba sobre los destacados resultados de las operaciones de la gendarmería al frente del coronel Sabas Lomelí, y se congratulaba de que gracias a sus servicios prestados al estado, la seguridad estaba garantizada, y la administración y el comercio dentro del territorio funcionaba con normalidad. ${ }^{31}$

No conformes, algunos meses después, Leopoldo Valencia, colaborador del periódico, visitó el cuartel de gendarmes del estado que entonces se hallaba instalado a un costado del templo de Jesús María, en el centro de la ciudad de Guadalajara. En vista de que al parecer hacían falta opiniones que contrarrestaran las críticas, Valencia declaró haber quedado sorprendido de ser recibido por el "digno jefe" y "caballeroso" general Lomelí, quien le mostró detalladamente el estado del inmueble, la escrupulosa limpieza que había dentro de él y del orden que se guardaba, al grado de contar con un propio hospital para gendarmes, condiciones que mejorarían, dijo muy convencido, la moral y complexión de sus elementos. De acuerdo con Valencia, las fuerzas militares del estado jamás habían alcanzado las mejores condiciones que hasta entonces se habían logrado, y labores como esa sólo merecían "la honra de las Administraciones a que pertenecen, y la de los Estados que así lo moralizan" ${ }^{32}$ En otro momento, Valencia volvería a depositar sus esperanzas en aquella fuerza policial y, especialmente, en sus soldados, pues con la llegada de Lomelí y el apoyo que depositó en él el gobierno del estado, quedó convencido de que vendría un progreso moral de los sectores populares que la constituían bajo la tutela e inspiración de las "capas superiores". De esa manera, pensó, se formaría un "soldado moderno", quien alejado de sus atavismos

${ }^{30}$ Art. 20, fracc. Ix del "Reglamento a que debe sujetarse la Gendarmería del Estado", Colección de los decretos (1823-1913, t. viII, $2^{\mathrm{a}}$. serie, p. 220).

${ }^{31}$ El Monitor Jalisciense, 1 de mayo de 1883, núm. 48, p. 1, Guadalajara.

${ }^{32}$ L. Valencia, "La Gendarmería del Estado", El Monitor Jalisciense, 16 de septiembre de 1883, núm. 65, p. 1. Guadalajara. 
salvajes y bárbaros (en el supuesto implícito de que en su mayoría eran indígenas), actuaría con mayor instrucción, solidaridad y conocimiento de la ley. ${ }^{33}$

A su vez, algunas editoriales de Juan Panadero se posicionaron contra las críticas que se desataban hacia la gendarmería del estado, en particular hacia el general Sabas Lomelí. Se enorgullecían de contar con una policía rural de tales características, un cuerpo destinado verdaderamente al servicio público: "porque de él dependen la seguridad, el orden y las garantías de que disfrutamos para comerciar, viajar y laborearla por esos mundos de Dios". En una editorial de 1890 hicieron recordar a sus lectores la impunidad con la que actuaban los bandidos en el estado, en particular durante los gobiernos de Ignacio Vallarta (1871-1875) y Fermín Riestra (1879-1882), cuando había ladrones por todas partes, en los caminos y garitas, y la sociedad no tenía momento de tranquilidad. Gracias a que Lomelí llegó a la gendarmería, agregaron, este hizo de tal cuerpo una institución honorable, al terminar con la holganza e indisciplina de sus elementos y al convertirla en un cuerpo tan bien constituido como la guardia civil española. En fin, en Juan Panadero no había sino loas para Lomelí: "Lomelí organizó su cuerpo de seguridad, le dio un reglamento que él mismo formuló, escogió sus oficiales, eligió sus casas fuertes, y produjo en un abrir y cerrar de ojos, una verdadera maravilla en aquel ramo tan desconceptuado. Es que Sabas tiene talento despejado, sabe organizar, y ha recibido de la naturaleza dotes especiales del mundo." ${ }^{34}$

Cabe mencionar que paralelamente a la normatividad que durante el último tercio del siglo xIx se gestó en torno a la organización de la gendarmería, otro tanto se hizo en relación con las acordadas, las cuales sólo se establecerían en los municipios y operarían en exclusivos casos de emergencia de seguridad a nivel local, particularmente para la persecución de gavillas. Una vez obtenido ese fin, las acordadas debían ser disueltas. A diferencia de la gendarmería, estas fuerzas quedarían plenamente a las órdenes de las autoridades locales. ${ }^{35}$ No obstante, las acordadas no desaparecieron, pues la crisis revolucionaria posterior a 1910 fue, a principio de cuentas, una nueva emergencia de seguridad que las vio fortalecerse.

${ }^{33}$ L. Valencia, "La inauguración del Hospital de Gendarmes”, El Monitor Jalisciense, 23 de septiembre de 1883, núm. 66, p. 2, Guadalajara.

${ }^{34}$ El Sr. Gral. D. Sabas Lomelí, Juan Panadero, 31 de agosto de 1890, núm. 2198, p. 1, Guadalajara.

${ }^{35}$ Colección de los decretos (1823-1913, t. vi, $2^{\text {a }}$. serie, pp. 351-354, 383). 
A finales del siglo xIx, la gendarmería ya estaba plenamente consolidada como proyecto interno de seguridad pública que replanteó la incipiente idea de la guardia nacional, como ya se había establecido desde las constituciones generales de 1824 y de 1857, en donde cada estado de la república debía encargarse de instruirla y reglamentarla. Además, en pleno porfiriato, el Cuerpo de Rurales creado durante ese mismo régimen, era insuficiente para cubrir todas las necesidades de seguridad en el país, pues apenas si podía distribuirse en los estados del centro con tan sólo 1600 elementos (Hernández Chávez, 2012, p. 66). Como contraste, en informe rendido en 1887 por el entonces gobernador de Jalisco, Francisco Tolentino (1883-1887) presumía de contar para el estado con una gendarmería que ascendía a los 700 hombres, casi la mitad de las fuerzas rurales de la federación. Cifra que ascendió en los últimos años del porfiriato a los cerca de 1000 elementos. El fortalecimiento de la gendarmería de Jalisco también puede comprenderse ante la desintegración de los escasos cuerpos rurales que operaban en Jalisco, cuyos jefes fueron incorporados a ella particularmente por el conocimiento que tenían del territorio y su dedicación para perseguir a los bandidos. ${ }^{36}$ Desde ese momento, los gobiernos sucesivos no tuvieron empero en destinar mayor presupuesto a la gendarmería, al grado de erigirse una enfermería para sus servicios, misma que admiró el periodista Leopoldo Valencia. Asimismo, se renovó el armamento, los uniformes de sus elementos y hasta los caballos de los escuadrones.

Ahora bien, si la gendarmería se constituía como la fuerza de seguridad que mejor había logrado Jalisco en lo que llevaba de su historia como entidad independiente, cabe preguntarse y explicar por qué desaparecería pocos años después (1911), justo en la crisis del movimiento revolucionario, y en la que debía ponerse a prueba su efectividad.

La crisis de la revolución que se vivió en México, y particularmente en Jalisco, repercutió con el cese de algunas instituciones que, para las posteriores autoridades revolucionarias, significaron un lastre del régimen anterior y un obstáculo para instaurar la nueva política. Cuando la rebelión maderista irrumpió en Jalisco, Francisco Madero nombró de manera interina a David Gutiérrez Allende al frente del gobierno de Jalisco (1911). A partir de entonces, la gendarmería comenzó a disolverse, dado que las fuerzas maderistas

${ }^{36}$ Francisco Tolentino, "Memoria presentada a la XI Legislatura del estado de Jalisco, por el C. Gobernador..., al concluir su periodo”. En Urzúa Orozco y Hernández (1988, t. II, p. 127). 
que se distribuyeron por el estado la asaltaban y se infiltraron en ella. Fue tal el desarrollo de las fuerzas maderistas que estas terminaron por sustituir a la gendarmería que, ante tal crisis posiblemente ya ni siquiera era lo suficientemente financiada. Tan pronto como fue establecida la revolución constitucional en Jalisco tiempo después, así como intentó acabar con todo resabio villista en la región, por igual comenzó a romper con instituciones del régimen anterior, como fue el caso de las jefaturas políticas en 1914, con la intención de darle libertad a los municipios. En su lugar, el entonces gobernador interino, Manuel Aguirre Berlanga, destinó delegados cantonales para verificar el funcionamiento de ese proyecto (Aldana, 1987, pp. 128-279). Aguirre Berlanga llegó al gobierno de Jalisco para sustituir a Manuel M. Diéguez, quien se unió a Venustiano Carranza para establecer la revolución constitucionalista en el Occidente. Como parte de su proyecto para terminar con previas instituciones y prácticas políticas que contravenían el nuevo régimen, por igual trató de irse contra los vicios y costumbres en clara acción de que su proyecto también implicó una reforma social. Así, lanzó el decreto núm. 74 (también denominada popularmente como "Ley Aguirre Berlanga") que prohibía la venta al menudeo de bebidas embriagantes; asimismo, lanzaría otro decreto para perseguir los juegos de azar. ${ }^{37}$ Tales prohibiciones no eran novedosas al menos para el caso de Jalisco, pues la embriaguez y el juego fueron las expresiones que normalmente se identificaron y persiguieron para erradicar la vagancia durante casi todo el siglo XIX (Isais, 2010).

Para entonces, la gendarmería ya estaba extinta y los constitucionalistas en Jalisco trataron de reorganizar la policía rural. Lo que quedó de aquella fuerza sólo fue su banda de música, la cual continuó denominándose "Banda de la Gendarmería del Estado" y representó a la entidad y al país en variedad de certámenes internacionales. ${ }^{38}$

Pese a la intermitente e informal operación de las acordadas a lo largo del siglo XIX, a principios del siglo xx los sucesivos gobiernos aún seguían confiando en ellas, pues en el rubro de la seguridad pública, Tomás López Linares, gobernador interino de Jalisco en 1917, anunció sobre los magníficos resultados que se habían obtenido tras la formación de tales fuerza rurales, necesarias para la extinción del bandolerismo, y para dotarlas de mayor for-

\footnotetext{
${ }^{37}$ Manuel Aguirre Berlanga, "Informe que da la gestión política y administrativa del gobierno constitucionalista de Jalisco". En Urzúa Orozco y Hernández (1988, t. III, pp. 82-83).

38 "Después del domingo", El Informador, 5 de agosto de 1918, p. 2, Guadalajara.
} 
malidad, se decretó que en cada municipio el presidente sería el jefe de ellas. Para entonces, en Jalisco operaban 298 acordadas, con un total de 2400 elementos. De igual manera, debían ser organizadas por los hacendados, y las últimas circulares los presionaban para hacerlo; de lo contrario, y recordando la legislación del siglo xIX, serían declarados enemigos del gobierno (circular núm. 34). Esto ante la firme convicción de que existían algunos "hacendados rebeldes" que mantenían o daban cobijo a ladrones. ${ }^{39}$

Un año después (1918), las acordadas casi se multiplicaron en el estado hasta alcanzar las 438, con poco más de 200 hombres, esto ante el aumento del bandolerismo y al creerse en la eficacia de las acordadas. Sin embargo, las autoridades no les daban toda su confianza porque eran organizadas por los más influyentes propietarios de cada región del estado, y por lo tanto, operaban sólo en beneficio de sus intereses. De tal manera, aunque ya se había experimentado el proyecto de la Gendarmería del Estado, estaba en puerta otro proyecto de seguridad, coordinado a través de la creación del Cuerpo Rural de Jalisco. ${ }^{40}$

\section{CONCLUSIONES}

Los estudios históricos sobre las policías en México afortunadamente se han incrementado en los últimos años; sin embargo, la mayoría de ellos se han dedicado a entender la organización y funcionamiento de las policías urbanas. Así, el presente estudio puede considerarse también un acercamiento al estudio de las policías rurales en México, cuyas operaciones dependieron de las necesidades que cada entidad colocó en su sistema de seguridad pública; y donde las necesidades y conflictos resultaban distintos a los que experimentaron las ciudades. El estudio visto hasta aquí reconstruye el desarrollo de un cuerpo de seguridad considerado muy tangencialmente en la historiografía jalisciense; sin embargo, tampoco puedo advertir que se trate de un estudio pormenorizado de la gendarmería de Jalisco, pues faltaría corroborar su normatividad e impresiones de la opinión pública con su ejercicio cotidiano,

39 Tomás López Linares, "Memoria leída por el Ejecutivo del Estado el 23 de mayo de 1917, ante el H. Congreso”. En Urzúa Orozco y Hernández (1998, t. III, pp. 127-128).

${ }^{40}$ Emiliano Degollado, "Informe que rindió el C. Gobernador Sustituto del Estado Lic. ..., el 1ํ de febrero de 1918 ante la XXV H. Legislatura”. En Urzúa Orozco y Hernández (1988, t. III, p. 174). 
lo cual deberá plantearse en una próxima investigación. Quizá el tema deba tomar todavía mayor interés en otras entidades del país para comprender el funcionamiento de las policías rurales a pesar de que se cuente con estudios que nos hablen sobre la criminalidad e inseguridad. Tampoco se trata de acudir a una mirada más institucional de la seguridad pública, en el entendido de que, por muchos años, incluso en la historia del tiempo presente, las policías se constituían por la sociedad misma pues, así como los comisarios y jefes políticos se movían por intereses propios y hasta de clase, los elementos que estaban a su mando no actuaban de diferente manera.

En este recorrido de poco más de 100 años, nos encontramos con un control social a nivel local que casi la mayor parte del tiempo fue administrado y financiado sin el Estado o las instituciones a través de las acordadas. Pero al correr la segunda mitad del siglo xix existió un aparente intento de monopolizar la seguridad pública a través de un cuerpo que sólo obedeciera a un mando supremo: el gobernador. El siglo XIX fue en buena medida un periodo que llevó a la formación de un Estado capaz de manifestarse en todas sus aristas (en lo comercial, administrativo, judicial o legislativo) y en todo el territorio (algo que apenas si pudo formalizarse durante el porfiriato). El problema de la seguridad en el campo no fue un problema que haya resuelto la posrevolución; intentos hubo varios, ya sea a través del ejército o policías federales, lo cual en últimas fechas ya no sólo no convence e intimida a las elites, sino a la población civil. El debate que actualmente se presenta en cuanto a la forma de organizar y garantizar la seguridad pública a nivel nacional, estatal y municipal, fue la constante en el largo siglo xix. Así como se discutía sobre la ineficacia de las policías urbanas o municipales, también se debatía sobre la conformación civil o militar de los cuerpos de seguridad, en este caso, la gendarmería del estado. Este debate hoy está por demás presente bajo el tema de la nueva Guardia Nacional, cuerpo que viene a sustituir a la Policía Federal y sobre el que la opinión pública divide su opinión por su adiestramiento y el tipo de mando, pero que se instala ante la lógica e impulsos que mueven a un cambio de régimen: disolver las corporaciones de gobiernos anteriores que no fructificaron, o bien, se corrompieron. 


\section{LISTA DE REFERENCIAS}

Aldana Rendón, M. (1987). Jalisco desde la revolución. Del reyismo al nuevo orden constitucional, 1910-1019 (vol. I). Guadalajara: Universidad de Guadalajara/Gobierno del Estado de Jalisco.

Agüero, A. (2018). Castigar y perdonar cuando conviene a la República. La justicia penal de Córdoba del Tucumán, siglos XVII y xVIII. Madrid: Centro de Estudios Políticos y Constitucionales.

Barriera, D. (coord.) (2010). La justicia y las formas de autoridad. Organización política y justicias locales en territorios de frontera. El Río de la Plata, Córdoba, Cuyo y Tucumán, siglos XVIII y XIX. Rosario: ISHIR CONICEY-Red Columnaria.

Bazán Alarcón, A. (1964). El Real Tribunal de la Acordada y la delincuencia en la Nueva España. (Tesis de maestría). México, Facultad de Filosofía y Letras-unAm.

Becerra Jiménez, C. G. (2008). Gobierno, justicia e instituciones en la Nueva Galicia. La alcaldía mayor de Santa María de los Lagos, 1563-1750. Guadalajara: Universidad de Guadalajara.

Bishop, A. (1852). Travels of Anna Bishop in Mexico, 1849. Filadelfia: Published by Charles Deal.

Colección de los decretos (1823-1913). Colección de los decretos, circulares y órdenes de los poderes Legislativo y Ejecutivo del estado de Jalisco ( $1^{\mathrm{a}}$ y $2^{\mathrm{a}}$ series, 40 vols.). Guadalajara: Tip. de S. Banda.

Dávalos, M., Hernández Franyuti, R. y Pulido Esteva, D. (coords.). (2017). Orden, policía y seguridad. Historia de las ciudades. México: INAH/Secretaría de Cultura.

Evans, A. S. (1870). Our sister republic: A gala trip through tropical Mexico in 1869-70. Hartford: Columbian Book Company.

Forbes, A. C. (1851). A trip to Mexico or recollections of a ten mounths' ramble in 1849-50, by a barrister. Londres: Smith, Eldee, and Co. Collxhill.

Fradkin, R. (comp.) (2008). El poder y la vara. Estudios sobre la justicia y la construcción del Estado en el Buenos Aires rural (1780-1830). Buenos Aires: Prometeo.

Gálvez Ruiz, M. Á. (1996). La conciencia regional en Guadalajara y el gobierno de los intendentes (1786-1800). Guadalajara: Unidad Editorial del Gobierno de Jalisco.

Gutiérrez Gutiérrez, J. A. (1991). Los Altos de Jalisco. Panorama histórico de una región y de su sociedad hasta 1821. México: Conaculta.

Hernández Chávez, A. (2012). Las fuerzas armadas mexicanas. Su función en el montaje de la República. México: El Colegio de México.

Hidalgo Nuchera, P. (2013). Antes de la Acordada. La represión de la criminalidad rural en el México colonial (1550-1750). Sevilla: Universidad de Sevilla. 
Isais Contreras, M. Á. (2010). Vagos y perniciosos en Jalisco (1967-1886). Una aproximación a la marginación y la reintegración forzada. México. (Tesis de maestría). México, Facultad de Filosofía y Letras-UnAm.

Isais Contreras, M. Á. (2017). Usos y prácticas en el campo jalisciense. Ahualulco de Mercado y Lagos de Moreno frente al último embate de las reformas liberales (1873-1905). (Tesis de doctorado). México, El Colegio de Michoacán.

MacLachlan, C. M. (1976). La justicia criminal del siglo XVIII en México. Un estudio sobre el tribunal de la Acordada. México: Secretaría de Educación Pública.

Manifestación (1848). Manifestación que el Supremo Tribunal de Justicia del Estado Libre de Jalisco, hace a los habitantes del mismo. Guadalajara: Imprenta de Manuel Brambila.

Montgomery, B. G. (1973). The evolution of rural justice in New Spain, culminating in the Acordada, and attempts by the Spanish Crown to institute the tribunal in Peru. (Tesis de doctorado). Loyola University.

Nacif Mina, J. (1986). La policía en la historia de la ciudad de México. México: Departamento del Distrito Federal.

Novísima recopilación de las leyes de España (1829). Novísima recopilación de las leyes de España. Contiene sus tres índices generales, y el suplemento correspondiente a los años de 1805 y 1806. (Tomo vi). Madrid: Don Julián Viana Razola.

Proyecto (1848). Proyecto de ley contra ladrones, asesinos y perjuros, presentado al Supremo Gobierno del Estado, en cumplimiento de su encargo, por la Comisión del Supremo Tribunal de Justicia, unida a la del Excmo. Consejo. Guadalajara: Imprenta de Manuel Brambila.

Pulido Esteva, D. (2017). Gendarmes, inspectores y comisarios: historia del sistema policial en la ciudad de México, 1870-1930. Ler História, 70, 37-58. DoI: https://doi. org/10.4000/lerhistoria.2696

Rojas Gómez, M. (2008). Las voces de la justicia. Delito y sociedad en Concepción (18201875). Atentados sexuales, pendencias, bigamia, amancebamiento e injurias. Santiago: DIBAM.

Rojas Sosa, O. M. (2012). "Cada uno viva su ley". Las controversias entre el Tribunal de la Acordada y la Real Sala del Crimen, 1785-1793. Estudios de Historia Novohispana, 47, 127-159.

Trujillo Bretón, J. A. (2010). En el camino real. Representaciones, prácticas y biografías de los bandidos en Jalisco, México, 1967-1911. Letras Históricas, 2, 105-132. Recuperado de http://www.letrashistoricas.cucsh.udg.mx/index.php/LH/article/ view $/ 2037$

Urzúa Orozco A. y G. Hernández (inv., comp. y notas) (1988). Jalisco, testimonio de sus gobernantes (tomos I-III). Guadalajara: Gobierno del estado de Jalisco. 
Vanderwood, P. (1982). Los rurales mexicanos. México: Fondo de Cultura Económica.

Vanderwood, P. (1986). Desorden y progreso. Bandidos, policías y desarrollo mexicano. México: Siglo XXI.

Villarroel, H. (1994). Enfermedades políticas que padece la capital de esta Nueva España en casi todos los cuerpos de que se compone y remedios que se le deben aplicar para su curación si se requiere que sea útil al rey y al público. México: Conaculta.

Yáñez Romero, J. A. (1999). Policía mexicana: cultura política, (in)seguridad y orden público en el gobierno del Distrito Federal, 1821-1876. México: Universidad Autónoma Metropolitana/Plaza y Valdés Editores.

Young, E. van (1989). La ciudad y el campo en el México del siglo xVIII. La economía rural de la región de Guadalajara 1675-1820. México: Fondo de Cultura Económica.

\section{OTRAS FUENTES}

Archivos

BNLB Biblioteca Nettie Lee Benson: Ignacio Vallarta Papers. Universidad de Texas en Austin.

BPej, Ahrag Biblioteca Pública del Estado de Jalisco "Juan José Arreola", Archivo Histórico de la Real Audiencia de Guadalajara.

Internet Archive: https://archive.org/ 